\title{
The Recent Application of the OSTRC Boxing Injury Prevention Program among Boxers in the Gulf Cooperation Council Countries
}

\author{
Wesam Saleh A. Al Attar ${ }^{1,2, *}$, Walaa Abutaleb ${ }^{1}$, Nada Alhazmi ${ }^{1}$, Hussain S. Ghulam ${ }^{3}$ \\ ${ }^{1}$ Department of Physical Therapy, Faculty of Applied Medical Sciences, Umm Al Qura University, Saudi Arabia \\ ${ }^{2}$ Discipline of Exercise and Sport Science, Faculty of Medicine and Health Sciences, The University of Sydney, Australia \\ ${ }^{3}$ Department of Physical Therapy, Faculty of Applied Medical Sciences, Najran University, Saudi Arabia
}

Received October 11, 2021; Revised December 8, 2021; Accepted December 27, 2021

\section{Cite This Paper in the following Citation Styles}

(a): [1] Wesam Saleh A. Al Attar, Walaa Abutaleb, Nada Alhazmi, Hussain S. Ghulam, "The Recent Application of the OSTRC Boxing Injury Prevention Program among Boxers in the Gulf Cooperation Council Countries," International Journal of Human Movement and Sports Sciences, Vol. 10, No. 1, pp. 14 - 21, 2022. DOI: 10.13189/saj.2022.100103.

(b): Wesam Saleh A. Al Attar, Walaa Abutaleb, Nada Alhazmi, Hussain S. Ghulam (2022). The Recent Application of the OSTRC Boxing Injury Prevention Program among Boxers in the Gulf Cooperation Council Countries. International Journal of Human Movement and Sports Sciences, 10(1), 14 - 21. DOI: 10.13189/saj.2022.100103.

Copyright $\bigcirc 2022$ by authors, all rights reserved. Authors agree that this article remains permanently open access under the terms of the Creative Commons Attribution License 4.0 International License

\begin{abstract}
Due to the high probability of injuries seen from boxing, together with the lack of assessment data examining the degree of risk to athletes, this study searched for solutions that may provide updated information to reduce or prevent the risk of injuries in this sport. This study aims to collect updated information about major injury risks among boxers and devise appropriate means to modify or prevent these risks by investigating the implementation of Oslo Sports Trauma Research Center (OSTRC) evidence-based injury prevention exercises among boxers. A survey was published containing a maximum of 23 multiple-choice questions from boxing associations in Gulf Cooperation Council (GCC) countries to 300 boxers in six GCC countries. A total of 261 boxers participated in the study, with core stability exercises being the most frequently implemented at a rate of $52.5 \%$. There were no statistically significant differences between the GCC countries in terms of the average number of injury prevention exercises performed. Finally, all exercise programs were studied in terms of injury prevention, and shoulder stabilization exercises were the only ones where the implementation rates varied widely between the GCC countries. Effective injury prevention strategies must be implemented, an athlete injury form report must be submitted to facilitate this, and information must be collected about the mechanism of the injury.
\end{abstract}

Keywords Injury Prevention Program, Boxing, Compliance, Skadefri

\section{Introduction}

Boxing is one of the most popular combat sports worldwide. The International Boxing Association states that boxing first appeared in Egypt in approximately 3000 B.C. [32], and its first Olympic appearance was in $688 \mathrm{BC}$ at the $23^{\text {rd }}$ Ancient Olympic Games [19]. The "Amateur International Boxing Association" (AIBA) is the officially recognized world organization of boxing and has 196 affiliated national federations; the events best known for are the World Championship and the Olympic Games [8]. The organization's structure has subsequently changed and introduced steps to make boxing safer [29]. The amateur boxing competition match consists of three-minute rounds with a recovery period of one minute in between, and punches are permitted exclusively to the head and torso $[1,41,42,44]$.

There has always been some controversies in studies pertaining to boxing injury sites, with studies typically focusing on blows to the head, as this is the most injured 
body region, followed by the hands and fingers, with injuries visible as lacerations and bruises [20,37]. The potential risk of lacerating the vertebral artery, in addition to intracranial injuries, is also a suspected cause of death $[5,11,14,26]$. Moreover, many studies have discussed the long-term implications, such as intracranial injuries and neurodegenerative diseases $[14,16,38,39,40,45,46]$. Furthermore, superficial facial lacerations and injuries can be inflicted to the nose, eyes, teeth, and cervical spinal column, and a bilateral mandibular fracture can occur $[3,6,12,25]$. Injuries to the upper limbs (e.g., rupture of the subscapular tendon, hand, or scapular fracture) also occasionally take place $[28,36]$.

Irrespective of the heated debates that surround this sport and the types of injuries sustained, injury prevention exercises in this field are rare. Loosemore et al. [23] reported that the removal of headguards may lower the risk of acute brain injury in AIBA competitions. Additionally, it is hypothesized that the trauma rate will fall as boxers gain more experience without headguards and educational programs start to become effective. Drury et al. [10] discussed "hand and wrist injuries in boxing and the martial arts" and found that preventing hand injuries in boxing revolves around four central pillars: hand and wrist wraps/taping, modifications of glove padding and design, proper striking techniques, and proper conditioning. Rules and restrictions concerning taping in amateur boxing may lower injury rates; the designs of boxing gloves have significantly improved over the past 20 years. Additionally, a poorly coached striking technique can increase the impact on the metacarpals of the ring and small fingers, which can lead to fractures. Traditional martial arts training using proper techniques and correct target selection may lower the risk of injuries to the hands; this is an important part of preventing injuries to the wrists and hands $[10,43]$.

In 2013, the AIBA proposed rule changes in response to high injury rates. These regulation amendments included increasing the glove sizes, adjusting the scoring system, and banning the headgear. Therefore, amateur boxing and the type of boxing in the Olympics have largely moved toward safer conditions $[9,17]$. However, these rule changes were not inherently mirrored in professional boxing, with regular knockouts and high levels of injury frequently taking place [18]. Lemme et al. [22] reported that injuries to the upper extremities (UE) because of boxing were responsible for thousands of annual visits to the emergency department in the United States of America (USA). They also noticed significant declines in boxing-related UE injuries, which are potentially the result of the 2013 rule changes [22]. After 2011, the American Academy of Pediatrics investigated child and adolescent participation in boxing and stated that neither Canada nor the USA recorded injury rates among boxing participants [2].

To date, no data have been published in the literature regarding the effectiveness of implementing injury prevention exercises to prevent boxing injuries. In 2000, the Oslo Sports Trauma Research Center (OSTRC) was founded with the aim of focusing on the prevention of sports injuries and associated health issues. Skadefri which is evidence-based injury prevention exercise was developed for anyone participating in sports and provides information on common sports injuries, injury risk factors, and prevention exercises for some injuries based on each sport type, and it has been already proofed its effectiveness among professional basketball, handball, soccer, and volleyball players. This program (Skadefri) has a number of injury prevention exercises which include core stability, explosive partner squats, shoulder stability, supine neck strength + , raising and lowering, prone neck strength, advanced wheelbarrow, rowing, neck strength against wall, diagonal arm pulls, neck stability, forearm strength 2, wheelbarrow + , supine neck strength, forearm strength 1 , cockfight, and wiper. Therefore, the aim of this study is to investigate the implementation of "Skadefri" evidence-based injury prevention exercises among boxers from Gulf Cooperation Council (GCC) countries. This would provide evidence-based insights to coaches and players into whether Skadefri injury prevention exercises should be included and implemented in the training sessions for boxers to prevent overall injuries.

\section{Materials and Methods}

\subsection{Study Design and Questionnaire}

This study was a cross-sectional survey targeting GCCs' players. To date, no validated survey has addressed the implementation of OSTRC injury prevention exercises among boxers. Therefore, a survey was developed specifically for this study by several authors' expert experience in sport medicine and injury prevention programs. Pilot testing was conducted prior to the commencement of the study to assess the validity of each question. The survey was conducted on 30 GCC boxers, who were expected to represent the final testing cohort because of their diverse experiences. Each question was rated for clarity, comprehension, and appropriateness on a scale from 1.0 to 5.0 (lowest to highest). Questions that scored an average of fewer than 4.0 points on any parameter were considered weak in terms of clarity, comprehension, and appropriateness, and therefore were discarded. Nevertheless, any question that scored above 4.5 was considered suitable for the study.

Respondents were asked to answer all the survey questions before answering the next set of questions. Respondents answered a maximum of 23 questions categorized into three sections: (1) the study invitation and participation agreement, (2) socio-demographic questions, and (3) the implementation of OSTRC boxing injury prevention exercises. The questions were multiple-choice, and the scoring of each item was dichotomous (correct answer $=1$; incorrect answer $=0$ ). 
The maximum score of the survey was 17 , which was the sum of all items. This was then converted into a percentage score for ease of data analysis and data reporting. Similarly, the survey domain scores were transformed into percentages. When questions are correctly answered, higher scores reflect greater implementation and knowledge (potential correct answers ranging from 0 to 17). The respondents could see the total score, correct answers, and questions they missed immediately after submission. This project was reviewed and ethically approved by the Biomedical Ethics Committee at Umm Al Qura University, approval number. HAPO02K012202010465. Consent was obtained from each participant in the study before data collection began.

\subsection{Survey Software and Administration}

A survey invitation was distributed through the Saudi Arabia, UAE, Kuwait, Bahrain, Oman, and Qatar boxing federations. This provided a brief background of the survey and encouraged participation. Respondents who were interested clicked on a hyperlink that led them to the survey description. Once the participants had read the scope and aim of the study, they were asked to provide informed consent before being granted access to the survey. The survey was completed anonymously and electronically via a web-based form (Google Forms). Responses were limited to one response only and were provided voluntarily. The survey distribution was from June 2019 to October 2020.

\subsection{Sample Size and Data Analysis}

The target number of boxers was 300, with a 5\% margin of error at a $95 \%$ confidence level. Following data extraction, the data were revised, coded, and entered the statistical software IBM SPSS version 22 (SPSS, Inc. Chicago, IL). All statistical analyses were performed using two-tailed tests. Statistical significance was set at a p-value of less than 0.05. Comparative analysis (cross-tabulation) was also performed based on the frequency and percentage distribution for the study regions regarding different types of boxing exercises. Because of the small frequencies, the significance of the relations in a cross-tabulation was tested using the exact probability test. The mean number of different exercises was calculated after summing all "yes" responses for the different exercises. One-way analysis of variance (ANOVA) was used to test for differences in mean scores for the performed exercises among the different countries and divisions. An independent samples t-test was used to assess the differences in the mean scores of the performed exercises according to the boxers' ages and levels.

\section{Results}

The participants' sociodemographic characteristics are displayed in (Table 1). The total number of participants was 261 from the GCC countries. Of these, $31.4 \%$ were from Saudi Arabia, 69.3\% were aged 20-29 years, and $62.1 \%$ were amateur boxers. Almost $25 \%$ of the respondents were in the heavyweight division, while the fewest respondents $(14.9 \%)$ were in the welterweight division. The overall distribution of the injury prevention exercises among the study participants is shown in (Table 2 ). The results showed that core stability exercises were the most frequently implemented exercises (52.5\%). This was followed by explosive partner squats $(51.7 \%)$. Other exercises including shoulder stability, supine neck strength + , raising and lowering, and prone neck strength exercises were experienced by over half of the participating boxers. Conversely, the remaining assessed exercises were implemented by fewer than half of the participants, and the lowest implementation rate was for the wiper exercise at $43.3 \%$. Generally, the mean $( \pm \mathrm{SD})$ of the overall number of injury prevention exercises implemented by the current study boxers was $8( \pm 2)$, ranging from to $3-13$, with a median of 8 exercises. No statistically significant difference $(\mathrm{P}=0.128)$ was found between the GCCs in terms of the mean number of committed injury prevention exercises; the highest was in Oman with a mean of $8.7( \pm 2.0)$, and the lowest means reported were from Bahrain and Qatar at $7.9( \pm 2.0)$ and $7.9( \pm 2.1)$, respectively. Younger (20-29) boxers showed a higher mean number of implemented programs $[8.4( \pm 2.1)]$ compared to those aged 30-39 years [8.2 $( \pm 2)]$, amateur boxers $[8.4( \pm 2.1)]$, and professional boxers $[8.2( \pm 2.0)]$. Heavyweight boxers had the highest mean number of committed injury prevention programs at $8.5( \pm 2.3)$ compared to other weight divisions. However, these differences were all statistically non-significant, as all $\mathrm{P}$ values were $>0.05$. The data are presented in (Table 3 ). The differences between the GCCs in terms of each addressed injury prevention exercise are shown in (Table 4). Among all injury prevention programs, only the shoulder stability prevention exercise implementation rate was significantly different between the GCCs. The highest implementation rate was in Oman $(72.0 \%)$, while the lowest was in Bahrain (34.2\%), with a P-value of 0.042 . 
Table 1. Personal data and nationality of the study group participants

\begin{tabular}{|c|c|c|}
\hline Personal Data \& Country & No & $\%$ \\
\hline Saudi Arabia & 82 & $31.4 \%$ \\
\hline Kuwait & 46 & $17.6 \%$ \\
\hline Qatar & 39 & $14.9 \%$ \\
\hline Bahrain & 38 & $14.6 \%$ \\
\hline United Arab Emirates & 31 & $11.9 \%$ \\
\hline Oman & 25 & $9.6 \%$ \\
\hline \multicolumn{3}{|c|}{ Age } \\
\hline $20-29$ & 181 & $69.3 \%$ \\
\hline $30-39$ & 80 & $30.7 \%$ \\
\hline \multicolumn{3}{|c|}{ Level } \\
\hline Amateur & 162 & $62.1 \%$ \\
\hline Professional & 99 & $37.9 \%$ \\
\hline \multicolumn{3}{|c|}{ Divisions } \\
\hline Heavyweight & 64 & $24.5 \%$ \\
\hline Light heavyweight & 61 & $23.4 \%$ \\
\hline Middleweight & 51 & $19.5 \%$ \\
\hline Lightweight & 46 & $17.6 \%$ \\
\hline Welterweight & 39 & $14.9 \%$ \\
\hline
\end{tabular}

Table 2. Overall distribution of injury prevention exercises among study participants

\begin{tabular}{|c|c|c|}
\hline Injury Prevention Exercises & No & $\%$ \\
\hline Core stability & 137 & $52.5 \%$ \\
\hline Explosive partner squats & 135 & $51.7 \%$ \\
\hline Shoulder stability & 133 & $51.0 \%$ \\
\hline Supine neck strength + & 133 & $51.0 \%$ \\
\hline Raising and lowering & 132 & $50.6 \%$ \\
\hline Prone neck strength & 131 & $50.2 \%$ \\
\hline Advanced wheelbarrow & 130 & $49.8 \%$ \\
\hline Rowing & 130 & $49.8 \%$ \\
\hline Neck strength against wall & 129 & $49.4 \%$ \\
\hline Diagonal arm pulls & 128 & $49.0 \%$ \\
\hline Neck stability & 128 & $49.0 \%$ \\
\hline Forearm strength 2 & 127 & $48.7 \%$ \\
\hline Wheelbarrow + & 126 & $48.3 \%$ \\
\hline Supine neck strength & 125 & $47.9 \%$ \\
\hline Forearm strength 1 & 122 & $46.7 \%$ \\
\hline Cockfight & 117 & $44.8 \%$ \\
\hline Wiper & 113 & $43.3 \%$ \\
\hline \multicolumn{3}{|c|}{ Overall Number of Exercises } \\
\hline Range & \multicolumn{2}{|c|}{$3-13$} \\
\hline Mean \pm SD & \multicolumn{2}{|c|}{$8 \pm 2$} \\
\hline Median & \multicolumn{2}{|c|}{8} \\
\hline \multicolumn{3}{|c|}{ SD: Standard deviation } \\
\hline
\end{tabular}


Table 3. Distribution of the number of committed injury prevention exercises according to participants' personal data

\begin{tabular}{|c|c|c|c|c|}
\hline \multirow{2}{*}{ Factors } & \multicolumn{3}{|c|}{ Total } & \multirow{2}{*}{ P-value } \\
\hline & Range & Mean & SD & \\
\hline \multicolumn{4}{|l|}{ Country } & \multirow{7}{*}{.128} \\
\hline Bahrain & $4-12$ & 7.9 & 2.0 & \\
\hline Kuwait & $3-13$ & 8.6 & 2.2 & \\
\hline Oman & $5-13$ & 8.7 & 2.0 & \\
\hline Qatar & $4-12$ & 7.9 & 2.1 & \\
\hline Saudi Arabia & $3-13$ & 8.4 & 2.1 & \\
\hline United Arab Emirates & $4-13$ & 8.5 & 2.0 & \\
\hline \multicolumn{4}{|l|}{ Age } & \multirow{3}{*}{.336} \\
\hline $20-29$ & $3-13$ & 8.4 & 2.1 & \\
\hline $30-39$ & $4-13$ & 8.2 & 2.0 & \\
\hline \multicolumn{4}{|l|}{ Level } & \multirow{3}{*}{.336} \\
\hline Amateur & $3-13$ & 8.4 & 2.1 & \\
\hline Professional & $3-13$ & 8.2 & 2.0 & \\
\hline \multicolumn{4}{|l|}{ Divisions } & \multirow{6}{*}{.285} \\
\hline Heavyweight & $3-13$ & 8.5 & 2.3 & \\
\hline Light heavyweight & $3-12$ & 8.1 & 2.0 & \\
\hline Lightweight & $4-13$ & 8.6 & 2.2 & \\
\hline Middleweight & $4-13$ & 8.3 & 1.9 & \\
\hline Welterweight & $5-13$ & 8.2 & 2.0 & \\
\hline \multicolumn{4}{|c|}{ P: One Way ANOVA test \#: Independent t-test SD: Standard deviation } & \\
\hline
\end{tabular}

Table 4. The differences between the GCCs in terms of implementation of the addressed injury prevention exercises

\begin{tabular}{|c|c|c|c|c|c|c|c|c|c|c|c|c|c|}
\hline \multirow{3}{*}{ Activity } & \multicolumn{12}{|c|}{ Country } & \multirow{3}{*}{ P-value } \\
\hline & \multicolumn{2}{|c|}{ Bahrain } & \multicolumn{2}{|c|}{ Kuwait } & \multicolumn{2}{|c|}{ Oman } & \multicolumn{2}{|c|}{ Qatar } & \multicolumn{2}{|c|}{ Saudi Arabia } & \multicolumn{2}{|c|}{ United Arab Emirates } & \\
\hline & No & $\%$ & No & $\%$ & No & $\%$ & No & $\%$ & No & $\%$ & No & $\%$ & \\
\hline Prone neck strength & 15 & $39.5 \%$ & 26 & $56.5 \%$ & 12 & $48.0 \%$ & 22 & $56.4 \%$ & 41 & $50.0 \%$ & 15 & $48.4 \%$ & .673 \\
\hline Supine neck strength & 19 & $50.0 \%$ & 25 & $54.3 \%$ & 11 & $44.0 \%$ & 15 & $38.5 \%$ & 41 & $50.0 \%$ & 14 & $45.2 \%$ & .759 \\
\hline Shoulder stability & 13 & $34.2 \%$ & 23 & $50.0 \%$ & 18 & $72.0 \%$ & 22 & $56.4 \%$ & 45 & $54.9 \%$ & 12 & $38.7 \%$ & $.042 *$ \\
\hline Forearm strength 2 & 19 & $50.0 \%$ & 27 & $58.7 \%$ & 12 & $48.0 \%$ & 19 & $48.7 \%$ & 36 & $43.9 \%$ & 14 & $45.2 \%$ & .734 \\
\hline Forearm strength 1 & 22 & $57.9 \%$ & 22 & $47.8 \%$ & 9 & $36.0 \%$ & 16 & $41.0 \%$ & 36 & $43.9 \%$ & 17 & $54.8 \%$ & .457 \\
\hline Diagonal arms pull & 13 & $34.2 \%$ & 21 & $45.7 \%$ & 16 & $64.0 \%$ & 16 & $41.0 \%$ & 47 & $57.3 \%$ & 15 & $48.4 \%$ & .107 \\
\hline Core stability & 16 & $42.1 \%$ & 29 & $63.0 \%$ & 15 & $60.0 \%$ & 21 & $53.8 \%$ & 39 & $47.6 \%$ & 17 & $54.8 \%$ & .397 \\
\hline $\begin{array}{l}\text { Neck strength } \\
\text { against wall }\end{array}$ & 13 & $34.2 \%$ & 25 & $54.3 \%$ & 12 & $48.0 \%$ & 21 & $53.8 \%$ & 44 & $53.7 \%$ & 14 & $45.2 \%$ & .403 \\
\hline $\begin{array}{c}\text { Advanced } \\
\text { wheelbarrow }\end{array}$ & 15 & $39.5 \%$ & 25 & $54.3 \%$ & 12 & $48.0 \%$ & 20 & $51.3 \%$ & 41 & $50.0 \%$ & 17 & $54.8 \%$ & .794 \\
\hline Wiper & 18 & $47.4 \%$ & 18 & $39.1 \%$ & 14 & $56.0 \%$ & 13 & $33.3 \%$ & 40 & $48.8 \%$ & 10 & $32.3 \%$ & .274 \\
\hline $\begin{array}{c}\text { Supine neck strength } \\
+\end{array}$ & 25 & $65.8 \%$ & 25 & $54.3 \%$ & 12 & $48.0 \%$ & 14 & $35.9 \%$ & 40 & $48.8 \%$ & 17 & $54.8 \%$ & .184 \\
\hline Neck stability & 17 & $44.7 \%$ & 19 & $41.3 \%$ & 14 & $56.0 \%$ & 20 & $51.3 \%$ & 42 & $51.2 \%$ & 16 & $51.6 \%$ & .823 \\
\hline $\begin{array}{l}\text { Raising and } \\
\text { lowering }\end{array}$ & 22 & $57.9 \%$ & 22 & $47.8 \%$ & 13 & $52.0 \%$ & 16 & $41.0 \%$ & 41 & $50.0 \%$ & 18 & $58.1 \%$ & .684 \\
\hline Cockfight & 17 & $44.7 \%$ & 22 & $47.8 \%$ & 13 & $52.0 \%$ & 19 & $48.7 \%$ & 30 & $36.6 \%$ & 16 & $51.6 \%$ & .585 \\
\hline Wheelbarrow + & 17 & $44.7 \%$ & 25 & $54.3 \%$ & 11 & $44.0 \%$ & 21 & $53.8 \%$ & 36 & $43.9 \%$ & 16 & $51.6 \%$ & .806 \\
\hline Rowing & 21 & $55.3 \%$ & 18 & $39.1 \%$ & 11 & $44.0 \%$ & 17 & $43.6 \%$ & 44 & $53.7 \%$ & 19 & $61.3 \%$ & .346 \\
\hline $\begin{array}{l}\text { Explosive partner } \\
\text { squats }\end{array}$ & 17 & $44.7 \%$ & 25 & $54.3 \%$ & 13 & $52.0 \%$ & 16 & $41.0 \%$ & 46 & $56.1 \%$ & 18 & $58.1 \%$ & .581 \\
\hline & & & & 0.05 & & t); & & $\sigma_{1}$ & & ts, & 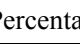 & & \\
\hline
\end{tabular}




\section{Discussion}

Many injury prevention programs were used before with deferent athletes and different sporting activities and they were found to be effective in preventing several injuries related to upper and lower extremities. These programs include the implementation of Nordic hamstring exercises to prevent hamstring injuries, the OSTRC cycling injury prevention program, the OSTRC back injury prevention program, the FIFA $11+$ injury prevention program, the FIFA 11+ Referees injury prevention program, and the Copenhagen adduction exercise.

This study assessed the rate of implementation of OSTRC boxing injury prevention exercises among boxers in several GCCs. Overall, the results indicate that the implementation rate was poor and did not differ by age or country. To the best of our knowledge, this is the first study to assess OSTRC boxing injury prevention exercises among boxers in GCCs, even globally, making it difficult to compare our results.

Results from large-scale randomized controlled trials showed that exercise-based prevention programs can significantly lower injuries among football players [4] and this could also be applicable to other sports, including boxing. Moreover, evidence and scientific-based injury prevention programs with regular performance could prove to have a protective effect on injury complaints in both the short and long terms [31]. In contrast with this study, which showed a low implementation rate, McCall et al. [24] reported high compliance with injury prevention measures. These differences between the findings could be attributed to a lack of knowledge about OSTRC boxing injury prevention exercises, barriers to implementation, unavailability, or inadequate time and equipment.

Core stability exercise as a part of the knee control exercise program reduced the rate of anterior cruciate ligament injuries by $64 \%$ in a trial involving over 4500 adolescent female players [35]. Of the boxers who participated in the current study, this exercise was the most implemented injury prevention exercise. Core training is a fundamental part of the boxing science training program due to the large correlation between trunk muscle mass and estimated punch force [7].

Shoulder stability exercise was the third most implemented injury prevention exercise and it was the only exercise shows significant differences among the GCCs in terms of implementation this exercise. These differences could be due to the fact that there are variations in the awareness level between the players and coaches in the GCCs. Therefore, action should be taken to determine these variations from the relative federations and increase their awareness and knowledge about the importance of this exercise by conducting seminars, workshops, and distributing booklets before practicing this sport.
In a previous study on elite athletes, risk factors, and injury prevention, the injury prevention strategy cited by interviewees most often involved muscle-strengthening exercises. Most participants reported that they included this strategy as part of their training or clinical treatment [30]. A previous systematic review found that the number of injury prevention programs that were based on training changes was larger in comparison to the total of programs that included changes in equipment or rules and educational strategies [13]. Among the programs that were based on preventative changes regarding training, most were focused on coordination, followed by interventions that were aimed at improving muscle power and strength [30].

Previous studies have highlighted that educating athletes on rehabilitation or training options could be one of the main factors in preventing sports injuries [33,34]. The lack of information on these injuries may hinder the efficacy of, and adherence to, injury prevention programs [15,21]. Moreover, the provision of performance-enhancing benefits in addition to injury prevention could help to change the attitudes of both athletes and coaches toward implementing injury prevention programs into a daily routine.

The number of injuries affecting boxers' performance and their absenteeism often increased, in addition to the high cost of their treatment. A recently published systematic review reported that sports-specific injury prevention programs strongly influence most performance indices and result in large-scale improvements to balance $(66 \%)$, power $(83 \%)$, strength $(75 \%)$, and speed/agility (62\%) [27]. These findings reinforce the importance of implementing an injury prevention exercise program among boxers, which could reduce injuries and their consequences.

Based on the results of the current study, the OSTRC boxing injury prevention program should reach multiple target players, program deliverers, and policymakers. This can be achieved by embedding the program in the education provided by coaches and into social media, apps, and websites. The compliance of boxers with the implementation of injury prevention programs could be increased by providing adequate supporting materials (apps, online resources, manuals), together with feedback, training, and mentoring.

Limitations of the current study include the small sample size, which is restricted to boxers from GCCs. Consequently, the results cannot be generalized globally. We did not assess the causes of non-implementation. Therefore, further large-scale studies are required to investigate this hypothesis.

\section{Conclusions}

This study found that the implementation of OSTRC boxing injury prevention exercises was poor; however, core stability exercises were most frequently implemented. 
This indicates that players and coaches should be aware of the importance of such programs; increasing their awareness and knowledge about this program is necessary and this can be performed through seminars, workshops, and booklets distributed before practicing this sport. Therefore, increasing the athletes' awareness would increase the practice level which might potentially reduce the risk of sustaining injuries. Core training is a fundamental part of boxing science training programs. Correspondingly, this does not diminish the importance of the other exercises. Nevertheless, effective injury prevention strategies must be implemented, and according to our need to collect more information about injury mechanisms, regular reports of player injuries will facilitate this. Moreover, further studies can be done to investigate the knowledge of athletes about the importance and effectiveness of such program and to investigate the reasons causing this low practice.

\section{Acknowledgements}

The authors would like to thank the Deanship of Scientific Research at Umm Al-Qura University for supporting this work by Grant Code: (22UQU4331100DSR01). The authors would like to thank all Boxers who participated in this project.

\section{REFERENCES}

[1] AIBA-Technical-Rules.pdf. Available from:http://boxingo ntario.com/wp-content/uploads/AIBA-Technical-Rules.pdf. (accessed 16.03.2021)

[2] American academy of pediatrics, council on sports medicine and fitness, canadian paediatric society, healthy active living and sports medicine committee. Boxing Participation by Children and Adolescents. Pediatrics, 2011, vol. 128 , no. 3 , pp. 617-623.

[3] Andrade RA, Evans PL, Almeida AL, Silva JD, Guedes AM, Guedes FR, Ranalli DN, Modesto A, Tinoco EM. Prevalence of dental trauma in Pan American Games athletes. International Association of Dental Traumatology, 2010, vol. 26, pp. 248-253. DOI.org/10.1111/j.1600-9657. 2010.00884.x

[4] Aspetar Sports Medicine Journal - Implementing injury prevention. Available from: https://www.aspetar.com/jour nal/viewarticle.aspx?id=406\#.YFgS1i0pCRs. (accessed 22.03.2021)

[5] Baird L.C., Newman C.B., Volk H., Svinth J.R., Conklin J., Levy M.L. Mortality Resulting From Head Injury in Professional Boxing. Neurosurgery, 2010, vol 67, no. 5, pp. 1444-1450.DOI.org/10.1227/01.NEU.0000373207.04297. 13

[6] Bledsoe G., Li G., Levy F. Injury Risk in Professional Boxing. The Southern Medical Journal, 2005, vol. 98, pp. 994-998.
[7] Boxing Training - Core Strength Training. Available from: https://boxingscience.co.uk/boxing-training-core/.(accesse d 22.03.2021)

[8] Chaabène H, Tabben M, Mkaouer B, Franchini E, Negra Y, Hammami M, Amara S, Chaabène RB, Hachana Y. Amateur Boxing: Physical and Physiological Attributes. Sports Medicine, 2015, vol 45, no. 3, pp. 337-352.

[9] Davis P., Connorton A., Driver S., Anderson S., Waldock R. The Activity Profile of Elite Male Amateur Boxing Following the 2013 Rule Changes. The Journal of Strength \& Conditioning Research, 2017, vol. 32. DOI: 10.1519/JSC.0000000000001864

[10] Drury B.T., Lehman T.P., Rayan G. Hand and Wrist Injuries in Boxing and the Martial Arts. Hand Clinics. 2017, vol. 33, no. 1, pp. 97-106. DOI: https://doi.org/10.1016/j.h cl.2016.08.004

[11] Elliott M.W. Boxing-related injuries in the US army, 1980 through 1985. Annals of Emergency Medicine, 1989, vol. 18 , no. 5 , pp. 598 .

[12] Emerich K., Nadolska-Gazda E. Dental trauma, prevention and knowledge concerning dental first-aid among Polish amateur boxers. The Journal of Science and Medicine in Sport, 2013, vol. 16, no. 4, pp. 297-301. DOI.org/10.1016/ j.jsams.2012.10.002

[13] Finch C.F. Implementation and dissemination research: the time has come! British Journal of Sports Medicine, 2011, vol. 45 , no. 10 , pp. $763-764$. DOI.org/10.1136/bjsports-20 11-090252

[14] Förstl H., Haass C., Hemmer B., Meyer B., Halle M. Boxing-Acute Complications and Late Sequelae. Dtsch Ärztebl Int, 2010, vol 47, pp. 835-839. DOI: 10.3238/arztebl.2010.0835

[15] Gabbe B.J. Re: A new framework for research leading to sports injury prevention. Journal of Science and Medicine in Sport, 2006;9(2):10.DOI.org/10.1016/j.jsams.2006.02.0 07

[16] Graham MR, Myers T, Evans P, Davies B, Cooper SM, Bhattacharya K, Grace FM, Baker JS. Direct Hits to the Head during Amateur Boxing is Associated with a Rise in Serum Biomarkers for Brain Injury. International Journal of Immunopathology and Pharmacology, 2011, vol. 24, no. 1, pp. 119-125. DOI.org/10.1177/039463201102400114

[17] Jako P. Safety measures in amateur boxing. British Journal of Sports Medicine, 2002 vol. 36, no. 6, pp. 394-395. DOI.org/10.1136/bjsm.36.6.394

[18] Jayarao M., Chin L.S., Cantu R.C. Boxing-Related Head Injuries. The Physician and Sportsmedicine, 2010, vol. 38, no. 3, pp. 18-26. DOI.org/10.3810/psm.2010.10.1804

[19] Jordan B. Medical Aspects of Boxing. CRC Press, 1992, pp. 354

[20] Jordan B., Campbell E.A. Acute Injuries Among Professional Boxers in New York State: A Two-Year Survey. The Physician and Sports medicine, 1988, vol. 16, no. 1, pp. 87-91. DOI.org/10.1080/00913847.1988.117094 07

[21] Keats M.R., Emery C.A., Finch C.F. Are we having fun yet? Fostering adherence to injury preventive exercise recommendations in young athletes. Sports Medicine 
Auckland NZ, 2012, vol. 42, no. 3, pp. 175-184.

[22] Lemme N.J., Ready L., Faria M., DeFroda S.F., Gil J.A., Owens B.D. Epidemiology of boxing-related upper extremity injuries in the United States. The Physician and Sports medicine, 2018, vol. 46, no. 4, pp. 503-508. DOI.org/10.1080/00913847.2018.1516478

[23] Loosemore M.P., Butler C.F., Khadri A., McDonagh D., Patel V.A., Bailes J.E. Use of Head Guards in AIBA Boxing Tournaments-A Cross-Sectional Observational Study. Clinical Journal of Sport Medicine, 2017, vol. 27, no 1, pp. 86-88. DOI: 10.1097/JSM.0000000000000322

[24] McCall A., Dupont G., Ekstrand J. Injury prevention strategies, coach compliance and player adherence of 33 of the UEFA Elite Club Injury Study teams: a survey of teams' head medical officers. British Journal of Sports Medicine, 2016, vol. 50, vol. 12, pp. 725-730. DOI.org/10.1136/bjsp orts-2015-095259

[25] Place H.M., Ecklund J.M., Enzenauer R.J. Cervical spine injury in a boxer: should mandatory screening be instituted? Journal of Spinal Disorders. 1996, vol. 1, pp. 64-67.

[26] Plant JR, Butt JC. Laceration of vertebral artery. An historic boxing death. The American journal of forensic medicine and pathology. 1993 Mar 1;14(1):61-4. DOI: 10.1097/00000433-199303000-00015

[27] Plummer A., Mugele H., Steffen K., Stoll J., Mayer F., Müller J. General versus sports-specific injury prevention programs in athletes: A systematic review on the effects on performance. PLOS ONE, 2019, vol. 14, pp. e0221346. DOI.org/10.1371/journal.pone.0221346

[28] Potter M.R., Snyder A.J., Smith G.A. Boxing Injuries Presenting to U.S. Emergency Departments, 1990-2008. The American College of Preventive Medicine, 2011, vol. 40, no. 4, pp. 462-467.DOI.org/10.1016/j.amepre.2010.12 .018

[29] QUALIFICATION SYSTEM - GAMES OF THE XXXI OLYMPIAD - RIO 2016.pdf. Available from: http://www.triathlon.org/uploads/docs/2014-02_-_Rio_201 6 - Qualification System - FINAL - Triathlon - EN _IOC_Comments.pdf. (accessed 22.03. 2021 )

[30] Saragiotto B.T., Di Pierro C., Lopes A.D., Saragiotto B.T., Di Pierro C., Lopes A.D. Risk factors and injury prevention in elite athletes: a descriptive study of the opinions of physical therapists, doctors and trainers. Brazilian Journal of Physical Therapy, 2014, vol. 18, no. 2, pp. 137-143. DOI.org/10.1590/S1413-35552012005000147

[31] Silvers-Granelli H, Mandelbaum B, Adeniji O, Insler S, Bizzini M, Pohlig R, Junge A, Snyder-Mackler L, Dvorak J. Efficacy of the FIFA 11+ Injury Prevention Program in the Collegiate Male Soccer Player. The American Journal of Sports Medicine, 2015, vol. 43, no. 11, pp. 2628-2637. DOI.org/10.1177/0363546515602009

[32] Swaddling J. The Ancient Olympic Games. University of Texas Press, 1999, pp. 120.

[33] Verhagen E., van Mechelen W. Sport for all, injury prevention for all. British Association of Sport and Excercise Medicine, 2010. DOI.org/10.1136/bjsm.2009.06 6316

[34] Verhagen E., van Stralen M.M., Van Mechelen W. Behaviour, the key factor for sports injury prevention.
Sports Medicine, 2010, vol. 40, no. 11, pp. 899-906.

[35] Waldén M., Atroshi I., Magnusson H., Wagner P., Hägglund M. Prevention of acute knee injuries in adolescent female football players: cluster randomised controlled trial. The BMJ, 2012, 344:e3042. DOI.org/10.1136/bmj.e3042

[36] Wyrsch R.B., Spindler K.P., Stricker P.R. Scapular fracture in a professional boxer. Journal of Shoulder and Elbow Surgery, 1995 , vol. 4, no. 5, pp. 395-398.

[37] Zazryn T. A prospective cohort study of injury in amateur and professional boxing. British Journal of Sports Medicine, 2006, vol. 40, no. 8, pp. 670-674. DOI.org/10.1136/bjsm.2 006.025924

[38] Goldfinger, M. H., Ling, H., Tilley, B. S., Liu, A. K., Davey, K., Holton, J. L., ... \& Gentleman, S. M. The aftermath of boxing revisited: identifying chronic traumatic encephalopathy pathology in the original Corsellis boxer series. Acta neuropathologica, 2018, vol. 136, no. 6, pp. 973-974. DOI.org/10.1007/s00401-018-1926-8

[39] Di Virgilio, T. G., Ietswaart, M., Wilson, L., Donaldson, D. I., \& Hunter, A. M. Understanding the consequences of repetitive subconcussive head impacts in sport: brain changes and dampened motor control are seen after boxing practice. Frontiers in human neuroscience, 2019, vol. 13, pp. 294 DOI.org/10.3389/fnhum.2019.00294

[40] Kariyanna, P. T., Charles, A., Ahmed, M. F., Jayarangaiah, A., Das, S., Al-Sadawi, M., ... \& McFarlane, S. I. Rare case of bilateral cerebellar hemorrhage in a male boxer. American journal of medical case reports, 2019, vol. 7 no. 10, pp. 236. DOI: 10.12691/ajmcr-7-10-4

[41] K1lıc, Y., Cetin, H. N., Sumlu, E., Pektas, M. B., Koca, H. B., \& Akar, F. Effects of boxing matches on metabolic, hormonal, and inflammatory parameters in male elite boxers. Medicina, 2019, vol. 55, no. 6, pp. 28. DOI.org/10.3390/medicina55060288

[42] Biggio, M., Bisio, A., Ruggeri, P., \& Bove, M. Defensive peripersonal space is modified by a learnt protective posture. Scientific reports, 2019, vol. 9, no. 1, pp.1-6. DOI:org/10.1038/s41598-019-43258-8

[43] Adamec, J., Hofer, P., Pittner, S., Monticelli, F., Graw, M., \& Schöpfer, J. Biomechanical assessment of various punching techniques. International journal of legal medicine, 2021, vol. 135, no. 3, pp. 853-859. DOI:org/10.1007/s00414-020-02440-8

[44] El-Ashker, S., Chaabene, H., Negra, Y., Prieske, O., \& Granacher, U. Cardio-respiratory endurance responses following a simulated $3 \times 3$ minutes amateur boxing contest in elite level boxers. Sports, 2018, vol. 6, no, 4, pp. 119 DOI:org/10.3390/sports6040119

[45] Zetterberg, H., Winblad, B., Bernick, C., Yaffe, K., Majdan, M., Johansson, G., ... \& Blennow, K. Head trauma in sports- clinical characteristics, epidemiology and biomarkers. Journal of internal medicine, 2019, vol. 285, no. 6, pp. 624-634. DOI:org/10.1111/joim. 12863

[46] Gallo, V., Motley, K., Kemp, S. P., Mian, S., Patel, T., James, L., ... \& McElvenny, D. Concussion and long-term cognitive impairment among professional or elite sport-persons: a systematic review. Journal of Neurology, Neurosurgery \& Psychiatry, 2020, vol. 91, no. 5, pp. 455-468 DOI:org/10.1136/jnnp-2019-321170 